\title{
A selective way to create defects by the thermal treatment of fluorinated double walled carbon nanotubes
}

\author{
Hiroyuki Muramatsu a, Kazunori Fujisawa a, Yong-Il Ko a, Kap-Seung Yang b, Takuya Hayashi a , \\ Morinobu Endo c, Cheol-Min Yang d, Yong Chae Jung d, Yoong Ahm Kim b,* \\ a Faculty of Engineering, Shinshu University, 4-17-1 Wakasato, Nagano 380-8553, Japan \\ b School of Polymer Science and Engineering, Chonnam National University, 77 Yongbong-ro, Buk-gu 500-757, Gwangju, Korea \\ c Institute of Carbon Science and Technology, Shinshu University, 4-17-1 Wakasato, Nagano 380-8553, Japan \\ dInstitute of Advanced Composite Materials, Korea Institute of Science and Technology, Chudong-ro 92, Bongdong-eup, Wanju-gun, Jeonbuk 565-905, \\ Korea
}

\section{A R T I C L E I N F O}

Article history:

Received 13 March 2014

Accepted 2 April 2014

Published 20 June 2014

\section{Keywords:}

Double walled carbon nanotube

Fluorination

De-fluorination

Defect engineering

Raman spectroscopy

\begin{abstract}
A B S T R A C T
Nanoscale defects in the outer tube to preserve the electrical and optical features of the inner tube can be engineered to exploit the intrinsic properties of double walled carbon nanotubes (DWCNTs) for various promising applications. We demonstrated a selective way to make defects in the outer tube by the fluorination of DWCNTs followed by the thermal detachment of the $\mathrm{F}$ atoms at $1000^{\circ} \mathrm{C}$ in argon. Fluorinated DWCNTs with different amounts of $\mathrm{F}$ atoms were prepared by reacting with fluorine gas at 25,200 , and $400{ }^{\circ} \mathrm{C}$ that gave the stoichiometry of $\mathrm{CF}_{0.20}, \mathrm{CF}_{0.30}$, and $\mathrm{CF}_{0.43}$, respectively. At the three different temperatures used, we observed preservation of the coaxial morphology in the fluorinated DWCNTs. For the DWCNTs fluorinated at 25 and $200{ }^{\circ} \mathrm{C}$, the strong radial breathing modes (RBMs) of the inner tube and weakened RBMs of the outer tube indicated selective fluorine attachment onto the outer tube. However, the disappearance of the RBMs in the Raman spectrum of the DWCNTs fluorinated at $400{ }^{\circ} \mathrm{C}$ showed the introduction of $\mathrm{F}$ atoms onto both inner and outer tubes. There was no significant change in the morphology and optical properties when the DWCNTs fluorinated at 25 and $200{ }^{\circ} \mathrm{C}$ were thermally treated at $1000{ }^{\circ} \mathrm{C}$ in argon. However, in the case of the DWCNTs fluorinated at $400{ }^{\circ} \mathrm{C}$, the recovery of strong RBMs from the inner tube and weakened RBMs from the outer tube indicated the selective introduction of substantial defects on the outer tube while preserving the original tubular shape. The thermal detachment of $\mathrm{F}$ atoms from fluorinated DWCNTs is an efficient way to make highly defective outer tubes for preserving the electrical conduction and optical activity of the inner tubes.
\end{abstract}

(C) 2014, Dalian Institute of Chemical Physics, Chinese Academy of Sciences. Published by Elsevier B.V. All rights reserved.

\section{Introduction}

In the last decade, the chemical introduction of $\mathrm{F}$ atoms onto the walls of single- and multi-walled carbon nanotubes (SWCNTs and MWCNTs) has been used for the nanotubes to improve dispersing ability in an organic solvent, control the electronic structure and tube length, and remove entrapped metal particles [1-8]. Double-walled carbon nanotubes (DWCNTs) consisting of two coaxial tubes have been used as a host carbon material for the fluorination reaction for the followings reasons: (a) better thermal stability and higher accessible surface areas than SWCNTs [9,10]; (b) the inner tubes

* Corresponding author. Tel: +82-62-5301871; Fax: +82-62-5301779; E-mail: yak@jnu.ac.kr DOI: 10.1016/S1872-2067(14)60107-8 | http://www.sciencedirect.com/science/journal/18722067 | Chin. J. Catal., Vol. 35, No. 6, June 2014 
with a small diameter below $1.0 \mathrm{~nm}$ have modified optical properties due to a coupling interaction with the outer tube [11-14]; and (c) the remarkable feature of performing a selective outer tube chemistry that leaves the inner tube intact [15-18].

The chemically introduced $\mathrm{F}$ atoms in host materials are thermally unstable when the fluorinated carbon materials are subjected to high temperatures [19-21]. Thus, the F atoms would detach from the carbon atoms of the host materials, thereby creating vacancies. In particular, a thermal annealing study of DWCNTs with selectively fluorinated outer tubes prepared by reacting with $\mathrm{BrF}_{3}$ and $\mathrm{Br}_{2}$ revealed that the optical properties of the inner tube were unchanged before and after the thermal treatment [16]. Thus, topological defects in the outer tube of DWCNTs can be engineered by the attachment and detachment of $\mathrm{F}$ atoms. This defect engineering allows DWCNTs to be utilized in many promising applications such as gas storage materials and electrode materials of supercapacitors and lithium ion batteries where the engineered defects are required for keeping the high electrical conductivity and desirable optical features of the inner tube. However, neither the effects of the high concentration of introduced $\mathrm{F}$ atoms (inner and outer tubes form covalent bonds with the F atoms) nor the subsequent thermal defluorination at high temperatures (up to $1000{ }^{\circ} \mathrm{C}$ ) on the structural and optical properties have been studied systematically. In this study, to elucidate unclarified points in the fluorination and thermal defluorination of DWCNTs in detail, we prepared fluorinated DWCNTs containing different amounts of $\mathrm{F}$ atoms by reacting DWCNTs with fluorine gas at 25,200 , and $400{ }^{\circ} \mathrm{C}$. The structural and optical changes of the fluorinated DWCNTs before and after thermal treatment were investigated using Raman, scanning electron microscopy (SEM), and transmission electron microscopy (TEM).

\section{Experimental}

The preparation procedure for synthesizing high purity DWCNTs using catalytic chemical vapor deposition was previously described [22,23]. To obtain high purity DWCNTs, we carried out a purification process ( $\mathrm{HCl}$ treatment and air oxidation up to $550{ }^{\circ} \mathrm{C}$ for $2 \mathrm{~h}$ ) in order to remove impurities (e.g., SWCNTs and catalytic particles). The fluorinated DWCNTs were prepared by the direct reaction with fluorine gas as follows. Before fluorination, the nanotube sample was vacuum treated at $200{ }^{\circ} \mathrm{C}$ for several hours to remove entrapped water. Then, the dried nanotubes were reacted with fluorine gas (1 atm) at 25,200 , or $400{ }^{\circ} \mathrm{C}$ for $5 \mathrm{~h}$. Finally, the fluorinated DWCNTs were thermally treated at $1000{ }^{\circ} \mathrm{C}$ in Ar to completely detach $\mathrm{F}$ atoms. The fluorinated and de-fluorinated DWCNTs were characterized by TEM (JEOL2010FEF), SEM (JEM6335Fs), X-ray photoelectron spectroscopy (XPS, Ulvac-phi model 5600, nonmonochromatized Mg- $K_{\alpha}$ at $1253.6 \mathrm{eV}$ ), and Raman spectroscopy (Kaiser Hololab 5000 system, laser excitation at 532 and $633 \mathrm{~nm})$.

\section{Results and discussion}

SEM and TEM observations showed that our DWCNTs were large bundles in the range of $10-50 \mathrm{~nm}$, with each tube existing in a hexagonal cross-section (Fig. $1(\mathrm{a}-\mathrm{c})$ ). It is observed that there was no noticeable change in bundle size and cross-sectional nature when the DWCNTs were fluorinated up to $200{ }^{\circ} \mathrm{C}$ (Fig. 1(d-i)). However, when the reaction temperature was increased to $400{ }^{\circ} \mathrm{C}$, we observed a perturbed cross-section nature as well as the formation of disordered carbon atoms attached on the outer tubes of the DWCNTs. The perturbed packing structure in the heavily fluorinated DWCNTs can be explained by a weakened interaction between the outer tubes

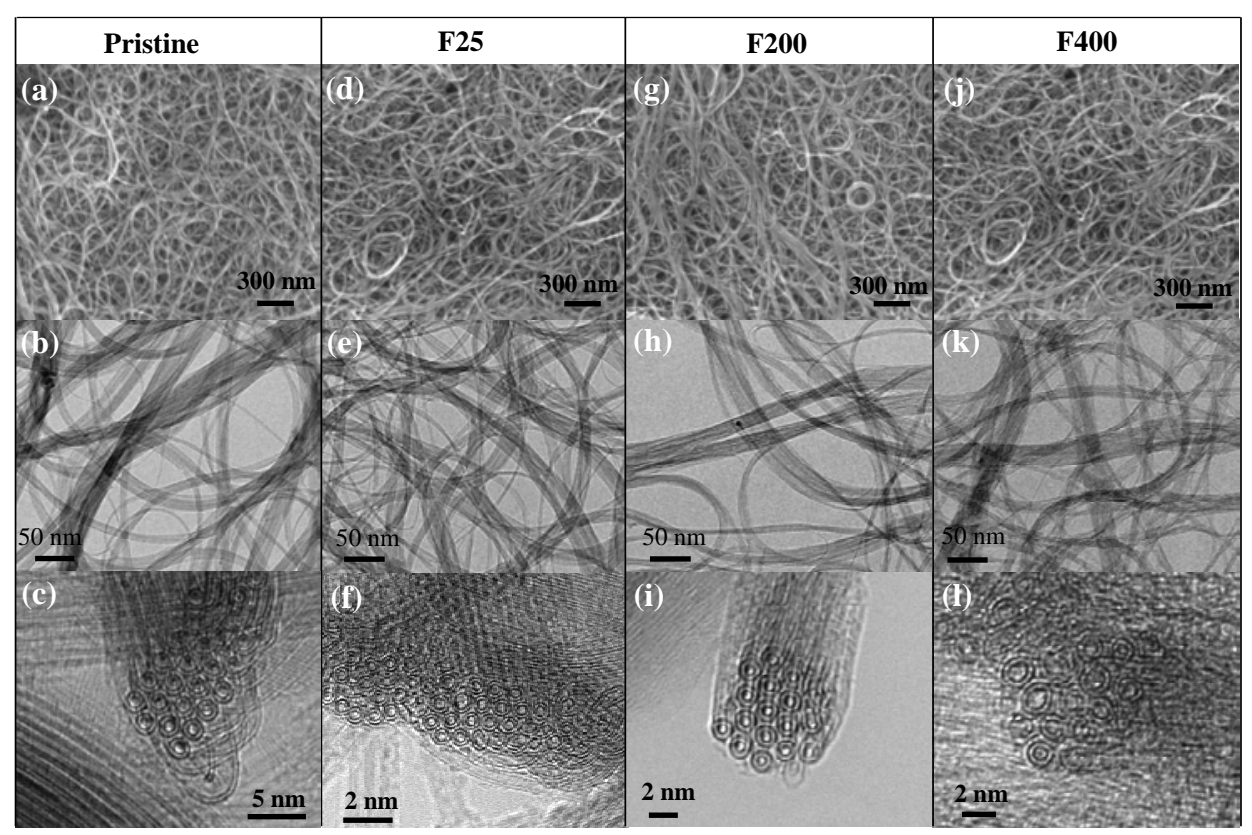

Fig. 1. SEM (a, d, g, j), low resolution TEM (b, e, h, k) and cross-section TEM (e, f, i, l) images of the pristine DWCNTs and the DWCNTs fluorinated at 25 (F25), 200 (F200), and $400^{\circ} \mathrm{C}$ (F400). Note that the coaxial structure was preserved after fluorination. 
of DWCNTs within a bundle. This is because both the outer and inner tubes would be decorated with $\mathrm{F}$ atoms at such a high reaction temperature. As revealed in our previous study [15], the inner tubes were unaffected at a reaction temperature of $200{ }^{\circ} \mathrm{C}$ because of the protection of the outer tubes. However, it is believed that fluorination also occurs on the inner tubes at a reaction temperature of $400{ }^{\circ} \mathrm{C}$. To verify this, we carried out XPS studies on the three types of DWCNTs fluorinated at 25, 200 , and $400^{\circ} \mathrm{C}$. The corresponding stoichiometry of the fluorinated DWCNTs was found to be $\mathrm{CF}_{0.20}, \mathrm{CF}_{0.30}$, and $\mathrm{CF}_{0.43}$, respectively. From this data, it can be said that the inner tubes were decorated with $\mathrm{F}$ atoms because it is probably that the open-tip morphology was formed in the air oxidation purification. Moreover, a typical TEM image of a heavily fluorinated DWCNT showed a much undulated and defective shell (Fig. 2). These kinds of defects can be formed by the intense gasification of fluoric carbon compounds [1].

To assess the degree of fluorination on the DWCNTs (inner and outer tubes), Raman spectra of the fluorinated DWCNT samples were taken using two different laser lines (532 and $633 \mathrm{~nm}$ ) (Fig. 3). There were several strong radial breathing modes (RBMs) below $350 \mathrm{~cm}^{-1}$ and a strong split G-band at $1590 \mathrm{~cm}^{-1}$ from the pristine DWCNTs [24]. The RBMs below $200 \mathrm{~cm}^{-1}$ originated from outer tubes with a large diameter above $1.0 \mathrm{~nm}$, while the RBMs above $200 \mathrm{~cm}^{-1}$ came from inner tubes with a diameter below $1.0 \mathrm{~nm}$. The absence of the D-band (defect-induced mode) indicated a highly crystalline DWCNT sample. With increasing fluorination temperature up to $200{ }^{\circ} \mathrm{C}$, we observed clearly depressed RBMs that were assigned to the outer tubes, as well as the concurrent increase in the intensity of the D-band. However, it is important to note that the RBMs assigned to the inner tubes were unchanged due to the protection by the outer tubes from the fluorine gas. The weakened RBMs assigned to the outer tubes can be explained by the loss of the Van Hove singularity due to the incorporation of a $s p^{3}$ moiety. However, when the fluorination temperature was increased to $400{ }^{\circ} \mathrm{C}$, we observed complete loss of the RBMs (including those of the inner tubes), as well as a strongly intensified D-band. Thus, the covalent bonding and high concentration

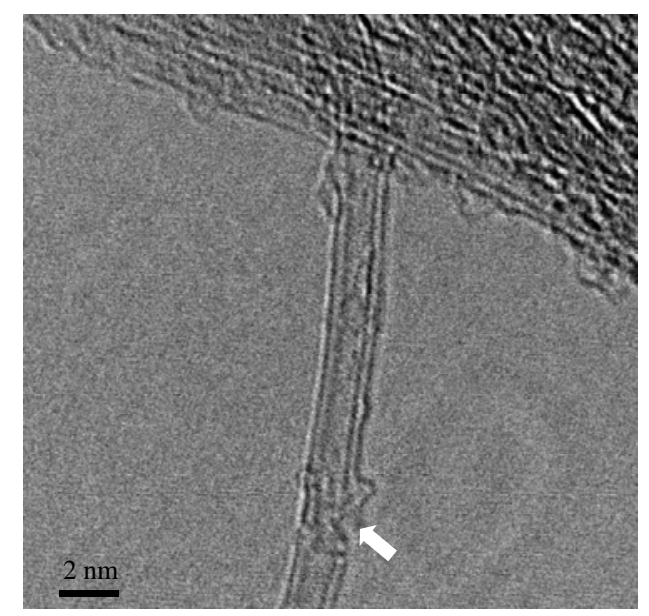

Fig. 2. Typical TEM image of the DWCNTs fluorinated at $400{ }^{\circ} \mathrm{C}$. Note that the inner and outer tubes were heavily damaged by fluorination.

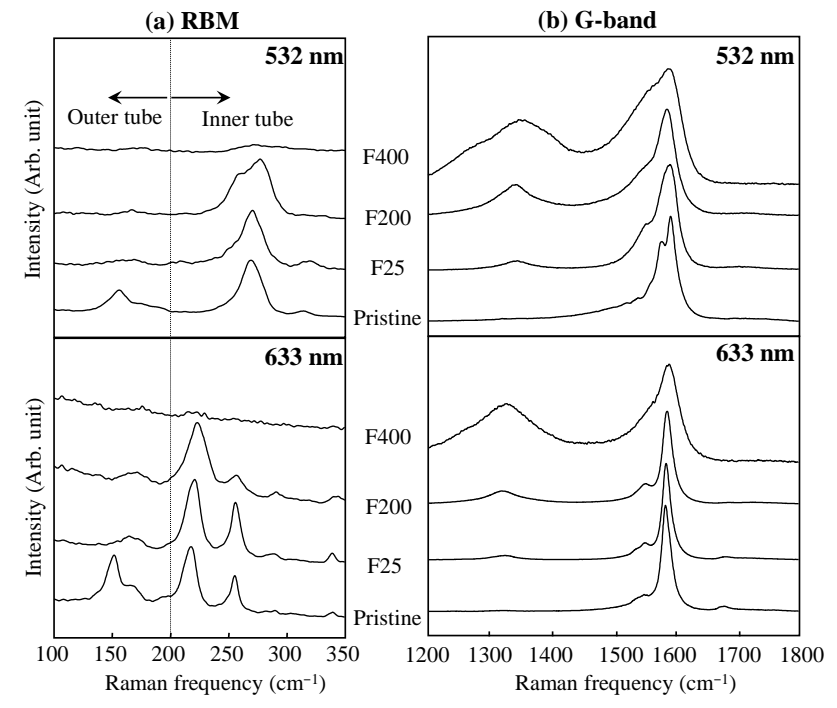

Fig. 3. Low (a) and high (b) frequency Raman spectra of the pristine DWCNTs and the DWCNTs fluorinated at 25,200 , and $400^{\circ} \mathrm{C}$ using two different laser lines.

of introduced $\mathrm{F}$ atoms on both the walls of the outer and inner tubes have induced a large change in the electronic features of the carbon nanotubes, which resulted in a loss of the resonance Raman effects. Moreover, because there was no difference in the RBM features of the metallic inner tubes in the Raman spectra obtained at $532 \mathrm{~nm}$ and the semiconducting inner tubes in the Raman spectra obtained at $633 \mathrm{~nm}$ as a function of reaction temperature (Fig. 3(a)), it can be concluded that there was no selective reactivity of fluorine gas with regard to metallic and semiconducting tubes.

In order to detach $\mathrm{F}$ atoms from the DWCNTs, the DWCNTs fluorinated at 25,200 , and $400{ }^{\circ} \mathrm{C}$ were thermally treated at $1000{ }^{\circ} \mathrm{C}$ for $1 \mathrm{~h}$ in Ar. The pristine DWCNTs were thermally stable up to $2000{ }^{\circ} \mathrm{C}$ in $\mathrm{Ar}$ atmosphere [9,25], and the results showed no visible change in the SEM images before and after the thermal treatment (Fig. 4(a-d)). However, low resolution TEM images of the annealed DWCNTs fluorinated at $400{ }^{\circ} \mathrm{C}$ (Fig. 4(j)) clearly showed the end structure of the bundled tubes, which were cut by the intense gasification of the high concentration of introduced $\mathrm{F}$ atoms during the high temperature thermal annealing, similar to the process in fluorinated SWCNTs [3]. Moreover, packing irregularities and deposited amorphous carbon on the nanotube bundles were clearly seen in the high resolution TEM images of the annealed DWCNTs fluorinated at 200 and $400{ }^{\circ} \mathrm{C}$ (Fig. 4 (g, k)). It can be suggested that the $\mathrm{F}$ atoms leave the carbon atoms during the thermal annealing, which create vacancies on the outer walls of the DWCNTs. The accumulation of defective sites by the intense gasification of fluorine-containing compounds during thermal annealing may be due to the formation of deposited carbon on the outer surface of the nanotubes, which also caused the packing irregularities. It is noteworthy that the length of the nanotube bundles in the annealed DWCNTs that were fluorinated at 25 and $200{ }^{\circ} \mathrm{C}$ was not changed as in de-fluorinated SWCNTs [3], indicating the defect-free structure of the inner 


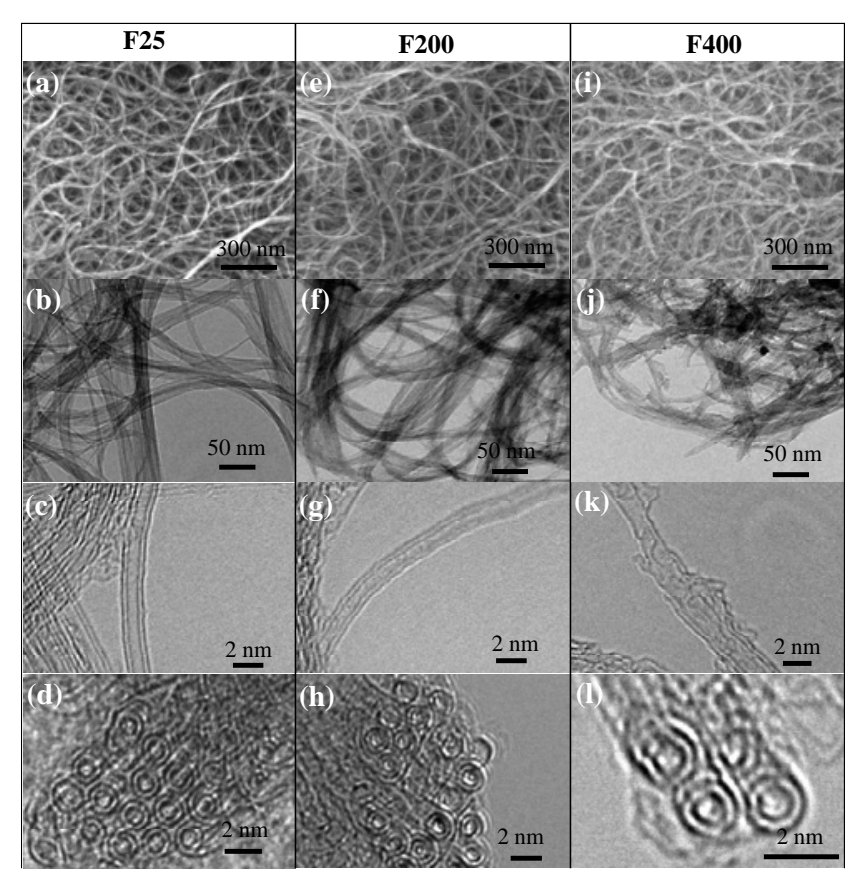

Fig. 4. SEM, low- and high-resolution, and cross-sectional TEM images for the thermally annealed DWCNTs fluorinated at 25,200 , and $400{ }^{\circ} \mathrm{C}$. Fig. $4(\mathrm{k})$ shows a peeled-off outer tube of the DWCNT, possibly due to intense etching ability of $\mathrm{F}$ atoms during the thermal treatment.

tubes. However, when the DWCNTs fluorinated at $400{ }^{\circ} \mathrm{C}$ was annealed at $1000^{\circ} \mathrm{C}$, we observed shortened bundles and partially peeled outer tubes (Fig. 4(k, l)). This result indicated the inhomogeneous distribution of $\mathrm{F}$ atoms in the inner and outer tubes.

Finally, to understand the structural recovery of the DWCNTs by thermal defluorination, Raman spectra were obtained using two different laser lines (532 and $633 \mathrm{~nm}$ ) (Fig. 5). For the de-fluorinated DWCNTs fluorinated at 25 and $200{ }^{\circ} \mathrm{C}$, the intensity of the RBMs assigned to the inner tubes was not

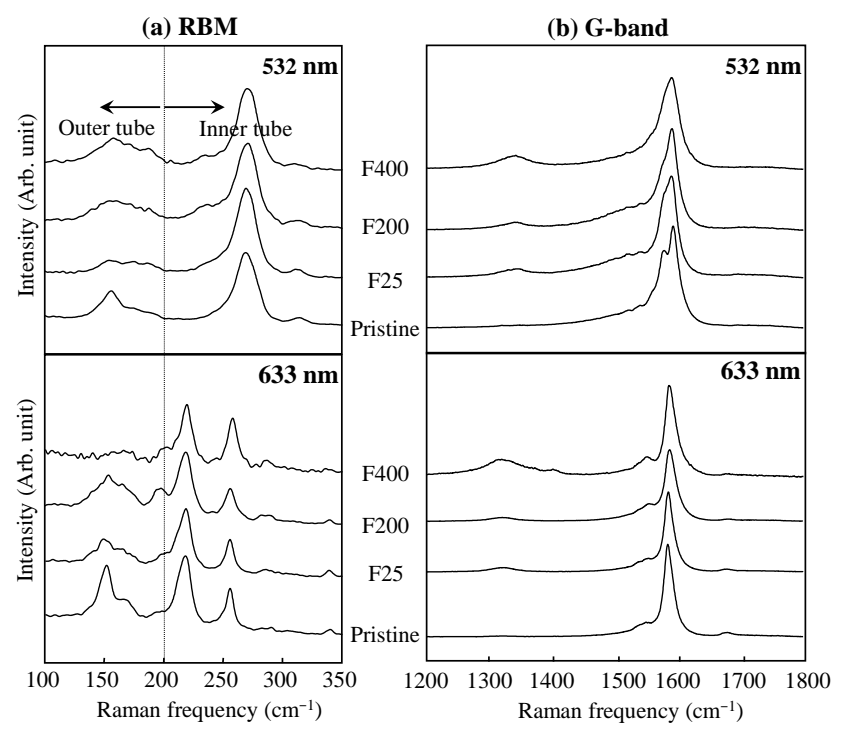

Fig. 5. Low (a) and high (b) frequency Raman spectra of the pristine DWCNTs and the thermally annealed DWCNTs fluorinated at 25, 200, and $400{ }^{\circ} \mathrm{C}$ using two laser lines. changed, while the RBMs assigned to the outer tubes showed partial recovery. Interestingly, the completely lost RBMs assigned to the inner tubes of the DWCNTs fluorinated at $400{ }^{\circ} \mathrm{C}$ were recovered, although there was only partial recovery after the thermal treatment of the RBMs assigned to the outer tubes. This recovery after the thermal treatment can be explained by the detachment of the localized $\mathrm{F}$ atoms on the wall of the inner and outer tubes. Although we observed a large amount of defects including peeled-off outer tubes from the thermal defluorination (Fig. $4(\mathrm{k}, \mathrm{l})$ ), the relatively low intensity of the D-band (Fig. 5(b)) was due to the fact that the resonance effect of the inner tubes dominated the Raman spectrum.

\section{Conclusions}

It was demonstrated that the coverage of $\mathrm{F}$ atoms on the inner and outer tubes of DWCNTs could be controlled by the reaction temperature with fluorine gas. The stoichiometry of DWCNTs fluorinated at 25,200 , and $400{ }^{\circ} \mathrm{C}$ was $\mathrm{CF}_{0.20}, \mathrm{CF}_{0.30}$, and $\mathrm{CF}_{0.43}$, respectively. For the DWCNTs fluorinated at 25 and $200{ }^{\circ} \mathrm{C}$, strong RBMs from the inner tubes and weakened RBMs from the outer tubes indicated selective fluorine attachment onto the outer tubes. However, complete loss of the RBMs for the DWCNTs fluorinated at $400{ }^{\circ} \mathrm{C}$ was due to the covalent bonding of $\mathrm{F}$ atoms onto both inner and outer tubes. When the fluorinated DWCNTs were thermally treated at $1000^{\circ} \mathrm{C}$, we observed stronger RBMs from the inner tubes, indicating a full recovery to its original tubular shape. With the successful thermal detachment of F atoms from fluorinated DWCNTs, this procedure can be used as an efficient way to make highly defective outer tubes for keeping the electrical conductive and optical properties of the inner tubes.

\section{Acknowledgments}

H.M. acknowledges the support from JSPS KAKENHI (24710115). Y.A.K. and K.S.Y. acknowledge the support from Global Research Laboratory (K2090300202412E010004010) through the National Research Foundation of Korea funded by the Ministry of Science, Information and Communication Technologies and Future Planning, Korea. Y.C.J. and C.M.Y. acknowledge the support from the Institutional Program of Korea Institute of Science and Technology (2Z04250). We also thank Prof. H. Touhara (Shinshu University) to provide the fluorinated DWCNTs.

\section{References}

[1] Mickelson E T, Huffman C B, Rinzler A G, Smalley R E, Hauge R H, Margrave J L. Chem Phys Lett, 1998, 296: 188

[2] Kawasaki S, Komatsu K, Okino F, Touhara H, Kataura H. Phys Chem Chem Phys, 2004, 6: 1769

[3] Gu Z, Peng H, Hauge R H, Smalley R E, Margrave J L. Nano Lett, 2002, 2: 1009

[4] Kudin K N, Bettinger H F, Scuseria G E. Phys Rev B, 2001, 63: 045413

[5] Mickelson E T, Chiang I W, Zimmerman J L, Boul P J, Lozano J, Liu J, Smalley R E, Hauge R H, Margrave J L. J Phys Chem B, 1999, 103: 


\section{Graphical Abstract}

Chin. J. Catal., 2014, 35: 864-868 doi: 10.1016/S1872-2067(14)60107-8

\section{A selective way to create defects by the thermal treatment of fluorinated double walled carbon nanotubes \\ Hiroyuki Muramatsu, Kazunori Fujisawa, Yong-Il Ko, Kap-Seung Yang, Takuya Hayashi, Morinobu Endo, Cheol-Min Yang, Yong Chae Jung, Yoong Ahm Kim * \\ Shinshu University, Japan; Chonnam National University, Korea; Korea Institute of Science and Technology, Korea}

The coverage of $\mathrm{F}$ atoms on the inner and outer tubes of DWCNTs was controlled by the temperature of reaction with fluorine gas, and a highly defective outer tube was generated by the detachment of fluorine that would preserve the electronic properties of the inner tube.

$$
4318
$$

[6] Yang C M, An K H, Park J S, Park K A, Lim S C, Cho S H, Lee Y S, Park W, Park C Y, Lee Y H. Phys Rev B, 2006, 73: 075419

[7] Bettinger H F. ChemPhysChem, 2003, 4: 1283

[8] Claves D, Rossignol J. Chem Phys Lett, 2009, 468: 231

[9] Kim Y A, Muramatsu H, Hayashi T, Endo M, Terrones M, Dresselhaus M S. Chem Phys Lett, 2004, 398: 87

[10] Muramatsu H, Hayashi T, Kim Y A, Shimamoto D, Kim Y J, Tantrakarn K, Endo M, Terrones M, Dresselhaus M S. Chem Phys Lett, 2005, 414: 444

[11] Bandow S, Hiraoka T, Yumura T, Hirahara K, Shinohara H, Iijima S. Chem Phys Lett, 2004, 384: 320

[12] Hertel T, Hagen A, Talalaev V, Arnold K, Hennrich F, Kappes M, Rosenthal S, McBride J, Ulbricht H, Flahaut E. Nano Lett, 2005, 5: 511

[13] Kishi N, Kikuchi S, Ramesh P, Sugai T, Watanabe Y, Shinohara H.J Phys Chem B, 2006, 110: 24816

[14] Shimamoto D, Muramatsu H, Hayashi T, Kim Y A, Endo M, Park J S Saito R, Terrones M, Dresselhaus M S. Appl Phys Lett, 2009, 94: 083106

[15] Muramatsu H, Kim Y A, Hayashi T, Endo M, Yonemoto A, Arikai H, Okino F, Touhara H. Chem Commun, 2005: 2002

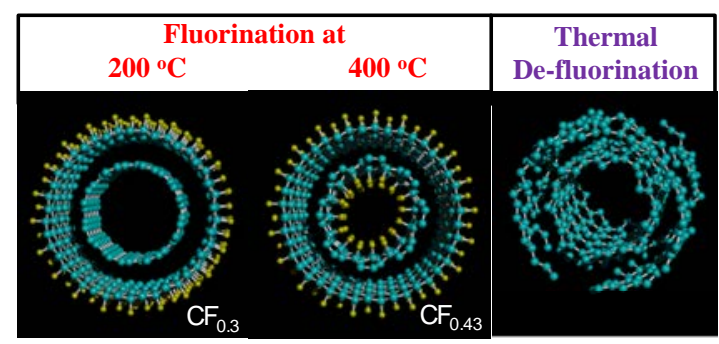

[16] Bulusheva L G, Gevko P N, Okotrub A V, Lavskaya Y V, Yudanov N F, Yudanova L I, Abrosimov O G, Pazhetnov E M, Boronin A I, Flahaut E. Chem Mater, 2006, 18: 4967

[17] Kawasaki S, Kanamori Y, Iwai Y, Okino F, Touhara H, Muramatsu H, Hayashi T, Kim Y A, Endo M. J Phys Chem Solids, 2008, 69: 1203

[18] Hayashi T, Shimamoto D, Kim Y A, Muramatsu H, Okino F, Touhara H, Shimada T, Miyauchi Y, Maruyama S, Terrones M, Dresselhaus M S, Endo M. ACS Nano, 2008, 2: 485

[19] Watanabe N, Nakajima T, Touhara H. Graphite Fluorides. Elsevier, Amsterdam, 1988

[20] Zhao W, Song C, Zheng B, Liu J, Viswanathan T. J Phys Chem B, 2002, 106: 293

[21] Pehrsson P E, Zhao W, Baldwin J W, Song C, Liu J, Kooi S, Zheng B. J Phys Chem B, 2003, 107: 5690

[22] Endo M, Muramatsu H, Hayashi T, Kim Y A, Terrones M, Dresselhaus M S. Nature, 2005, 433: 476

[23] Kim Y A, Muramatsu H, Hayashi T, Endo M, Terrones M, Dresselhaus M S. Chem Vapor Deposition, 2006, 12: 327

[24] Dresselhaus M S, Eklund P C. Adv Phys, 2000, 49: 705

[25] Endo M, Muramatsu H, Hayashi T, Kim Y A, Van Lier G, Charlier J C, Terrones H, Terrones M, Dresselhaus M S. Nano Lett, 2005, 5: 1099 